\title{
Pengaruh Motivasi, Komunikasi dan Budaya Organisasi terhadap Kinerja Karyawan
}

\author{
Eni Erwantiningsih \\ Fakultas Ekonomi, Universitas Merdeka Pasuruan, Indonesia \\ enierwanti232@gmail.com
}

\begin{abstract}
The purpose of this research is to analyze the influence of motivation, communication and organizational culture to employee performance. The object of this study is Merdeka University Pasuruan. Data collected through questionnaires given to 42 respondents of educational staff taken by census method. The results show that: 1) motivatian has a significant effect on employee performance, 2) communication does not have a significant effect on employee performanc,e 3) organizational culture has a significant effect on employee performance, and 4) organizational culture has a dominant effect on employee performance.
\end{abstract}

Keywords: Communication, Employee Performance, Motivation, Organizational Culture

\section{PENDAHULUAN}

Dalam perkembangan dunia kependidikan saat ini khususnya lembaga pendidikan tinggi, keberadaan Perguruan Tinggi Swasta sangat diperhitungkan perkembangannya di masa depan karena harus bersaing dengan Perguruan Tinggi Negeri diidentikkan dengan pemberian pelayanan, pemenuhan sarana dan prasarana serta kualitas lulusan yang lebih unggul dari Perguruan Tinggi Swasta. Menghadapi hal ini tentunya Perguruan Tinggi Swasta harus mampu mengelola dan meningkatkan potensi yang ada baik dari sisi karyawan maupun dalam pengelolaan secara mandiri sumber dana yang diperoleh dari masyarakat .

Cerminan tingginya kualitas sumber daya manusia dapat dilihat dari kinerja karyawannya karena hal ini penting dan potensial dalam pencapaian tujuan organisasi. Kinerja merupakan prestasi kerja karyawan yang ditunjukkan apakah tugas dan tanggungjawabnya selesai sesuai dengan waktu dan prosedur yang ada. Agar organisasi bisa tetap survive maka suatu organisasi harus terus memperbaiki kualitas sumberdaya manusia serta kualitas hubungan baik ke dalam maupun keluar sebagai cara untuk menghadapi perubahan dan memenangkan persaingan.

\section{Kinerja}

Kinerja merupakan hasil kerja yang jelas teramati sebagai prestasi kerja karyawan baik secara mutu maupun jumlah yang sesuai dengan kriteria pekerjaan dan tanggung jawab yang diberikan dan disesuaikan pula dengan target yang diharapkan oleh organisasi dalam usaha untuk mencapai tujuan organisasi pada waktu tertentu. Dikatakan juga oleh (Hasibuan, 2016) adalah prestasi yang ditunjukkan seseorang terkait penyelesaian setiap tugas dan tanggungjawab yang dibebankan kepadanya disesuaikan pada keahlian, pengalaman serta kesungguhan. 
Selanjutnya dikemukakan (Gibson, 1996) bahwa kinerja (job perfomance) adalah hasil kerja yang diharapkan dari perilaku. Berdasar pendapat dari (Moenir, 2016) bahwa "kinerja adalah sebagai hasil dari suatu pekerjaan atau prestasi seseorang pada suatu waktu tertentu dengan ukuran tertentu pula." Dikemukakan (AP Mangkunegara, 2009) kinerja adalah hasil pemikiran dan karya karyawan dilihat dari mutu dan jumlah yang buktikan atas penyelesaian pekerjaannya sesuai kewajiban dan beban yang diberikan.

Sedangkan (Rivai Veitzal, 2013) menyatakan kinerja adalah bentuk perilaku sebenarnya yang ditunjukkan oleh setiap orang atas prestasi kerjanya sesuai dengan peran dan tanggungjawabnya dalam perusahaan Dikatakan oleh (Dharma, 2012) dalam mengukur kinerja dipertimbangkan kualitas kerja, kuantitas kerja dan ketepatan waktu

\section{Motivasi}

Motivasi menurut (Uno, 2007) yaitu sebagai proses yang berperan dalam membantu seseorang mencapai tujuan hidupnya dengan arah serta ketekunan yang terbentuk karenanya. Motivasi merupakan energi dari dalam dan luar yang mendorong manusia untuk meraih harapan dan tujuan yang telah ditentukan atau motivasi bisa juga mengandung arti sebagai proses bagaimana orang lain atau karyawannya bisa dipengaruhi untuk beraktivitas serta menyelesaikan tugasnya sesuai penetapan tujuan yang telah dibuat sebelumnya.

(Fred, 1995) menegaskan juga bahwa motivasi merupakan urutan kejadian yang diawali dengan adanya situasi defisiensi kebutuhan fisiologis, psikologis dan lainnya yang mendorong sikap atau keinginan merujuk pada suatu tujuan tertentu atau insentif. Maka dari itu hal yang mendasar sebagai pemahaman proses motivasi ada pada hubungan antara dorongan, keinginan, dan insentif.

Dijelaskan juga (Terry \& Rue, 2019) bahwa motivasi adalah sesuatu yang melatarbelakangi seseorang untuk segera berkeinginan menyelesaikan tugasnya.

Teori motivasi yang kami jadikan dasar penelitian adalah teori Alderfer yaitu Teori ERG ( Exsistence, Relatedness, Growth ). Di dalam teori ini dijelaskan bahwa terdapat 3 pengelompokan atas kebutuhan dasar manusia yaitu :(1) Existence Needs ( kebutuhan eksistensi ); (2) Relatedness Needs (Kebutuhan Hubungan Sosial); (3) Growth Needs (Kebutuhan Pertumbuhan).

\section{Komunikasi}

Dalam suatu organisasi komunikasi termasuk kegiatan untuk melancarkan hubungan antara pimpinan dengan bawahannya. Mengingat pentingnya fungsi tersebut maka komunikasi perlu dilakukan secara maksimal sebagai upaya agar pesan serta maksud yang disampaikan seseorang dapat diterima serta dimengerti oleh orang lain. Ada beberapa pendapat tentang komunikasi, antara lain: (Newstrom \& Davis, 2002) "Komunikasi adalah suatu proses memindahkan informasi serta pemahaman dari satu orang ke orang lain". (Rakhmat, 2008) mengatakan bahwa "Suatu komunikasi akan menjadi lebih berkualitas serta sesuai kondisi apabila didukung oleh sikap saling percaya, jujur, dan empati diantara penyampai pesan serta penerima pesan".

Pendapat lainnya dikemukakan (Ardana, Mujiati, \& Utama, 2012) bahwa komunikasi adalah kunci untuk membuka hubungan serta kerjasama. Selain itu sebagai cara menyampaikan keinginan dan keberhasilannya dapat meningkatkan kerjasama.

(Purwanto, 2011) mengatakan "bahwa dalam struktur organisasi terdapat beberapa jabatan atau kedudukan dimana masing-masing mempunyai batas tanggungjawab dan wewenang. Dalam hubungannya dengan proses disampaikannya informasi dari bawahan kepada pimpinan ataupun sebaliknya." Adapun arus informasi dalam komunikasi dapat dikelompokkan sebagai komunikasi vertikal dan komunikasi horizontal. 


\section{Budaya Organisasi}

Suharto memberikan pandangannya terkait budaya organisasi merupakan nilai yang digunakan sebagai acuan dan digunakan seseorang untuk memecahkan setiap masalah, sebagai usaha beradaptasi saat bergabung dalam suatu lembaga sehingga setiap hal yang menjadi acuan perilaku dapat diketahui serta dipahami oleh semua anggota organisasi.

Dikemukakan oleh (Robbins \& Judge, 2008) " budaya organisasi (organizational culture) adalah nilai yang diyakini dan menjadi acuan seluruh anggota dan mampu membuat perbedaan dengan organisasi yang lain. Adapun karakteristik yang ada diantaranya : 1) Inovasi serta berani mengambil risiko (Inovation and risk taking ), 2) Perhatian kepada detil (Attention to detail), 3) Bertujuan kepada hasil (Outcome orientation), 4) Bertujuan kepada manusia (People orientation), 5) Bertujuan pada tim (Team orientation), 6) Agresivitas (Aggressiveness) dan 7) Stabilitas (Stability).

\section{Pengaruh Budaya Organisasi, Komunikasi dan Motivasi Terhadap Kinerja Karyawan}

Pola pikir dan cara pandang karyawan terhadap tugas dan tanggungjawabnya sangat menentukan bagaimana tujuan organisasi dapat dicapai melalui kinerja karyawan di dalamnya. Dimana cara pandang yang sudah diyakini sehingga menjadi ciri khas organisasi itu sendiri akan bermuara menjadi sebuah budaya didalamnya. Penelitian (Soedjono, 2005), (Taurisa Chaterina, 2012), (Arianty Nel, 2014), (Baan, 2015), (Prihono,Budhiarta, 2016) serta (Sagita, Susilo, \& Cahyo W.S, 2018) menyimpulkan terdapatnya pengaruh positif antara budaya organisasi terhadap kinerja.

Kinerja yang tinggi dalam suatu budaya organisasi yang kondusif juga dipengaruhi bagaimana cara anggota organisasi mampu berkomunikasi serta bekerjasama dengan rekan sekerja maupun atasan. Komunikasi dilakukan oleh seseorang baik di lingkungan organisasi kerja maupun di masyarakat untuk meningkatkan keakraban, saling pengertian serta memperlancar aktivitas. Penelitian terkait hal ini dilakukan oleh (Hastuti, Sularso, 2013),(Lakoy, 2015), (Srimiatun \& Prihatinta, 2017) serta (Samodro \& Lestari, 2018) diperoleh pembuktian empiris bahwa komunikasi berpengaruh terhadap kinerja karyawan.

Di sisi lain, prestasi kerja seseorang dibentuk oleh faktor dari luar dan dari dalam dirinya sendiri. Sebuah dorongan dalam diri individu akan menggerakkan seseorang untuk berusaha demi mencapai keinginan dan tujuannya. Penelitian (Hastuti, Sularso, 2013), (Rahmayanti, 2014), (Prihono, Budhiarta, 2016), (Amalia \& Fakhri, 2016) telah memberikan bukti secara signifikan bahwa motivasi mempengaruhi kinerja seorang karyawan.

Hipotesis pada penelitian ini sebagai berikut :

$\mathrm{H}_{1}$ : motivasi berpengaruh terhadap kinerja karyawan di Universitas Merdeka Pasuruan.

$\mathrm{H}_{2}$ : komunikasi berpengaruh terhadap kinerja karyawan di Universitas Merdeka Pasuruan.

$\mathrm{H}_{3}$ : budaya organisasi berpengaruh terhadap kinerja karyawan di Universitas Merdeka Pasuruan

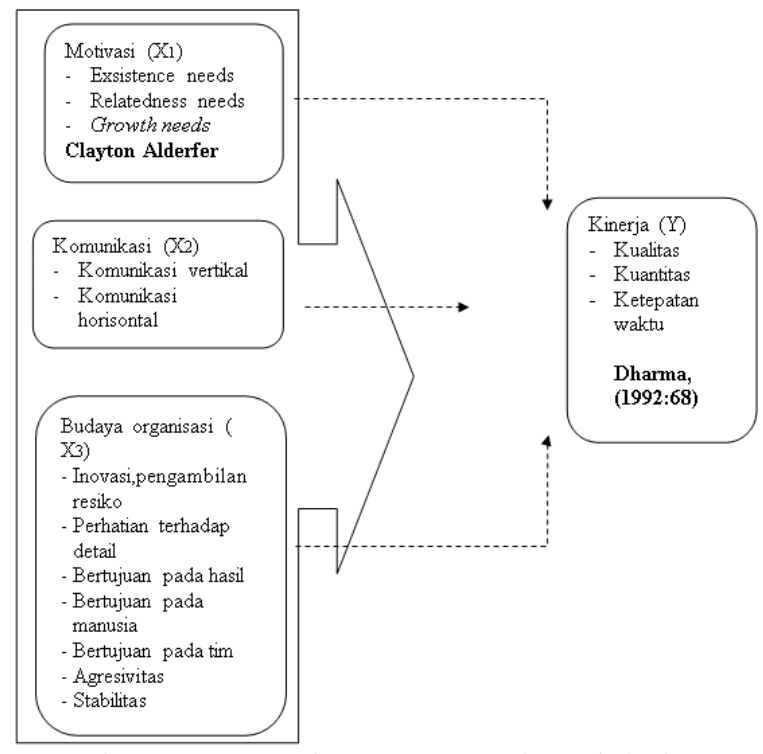

Gambar 1. Kerangka Konseptual Variabel 


\section{METODE}

\section{Jenis dan Sumber Data}

Data pada penelitian ini berupa data kuantitatif yang berasal dari jawaban responden atas kuesioner yang disebarkan serta disajikan berdasar skala likert. Adapun sumber data primer diperoleh langsung dari kuesioner yang diberikan ke karyawan administasi Universitas Merdeka Pasuruan sebagai obyek penelitian.

\section{Populasi dan Sampel}

Populasinya adalah seluruh karyawan administrasi di Universitas Merdeka Pasuruan yang berjumlah 42 orang dengan dengan masa kerja 2-5 tahun. Penelitian dilakukan secara sensus sehingga semua anggota populasi dijadikan sampel.

\section{Teknik Analisa Data}

Teknis analisa data pada penelitian ini menggunakan analisis linier berganda :

$$
\hat{\mathrm{Y}}=\alpha+\beta 1 \mathrm{X} 1+\beta 2 \mathrm{X} 2+\beta 3 \mathrm{X} 3+\mathrm{e}
$$

dengan keterangan :

$\begin{array}{ll}\mathrm{X} 1= & \text { motivasi } \\ \mathrm{X} 2= & \text { komunikasi } \\ \mathrm{X} 3= & \text { budaya organisasi } \\ \mathrm{e}= & \text { eror } \\ \mathrm{Y}= & \text { kinerja karyawan } \\ \alpha= & \text { konstanta } \\ \beta 1,2,3= & \text { koefsien regresi }\end{array}$

\section{Uji Validitas dan Reliabilitas}

Tujuan uji validitas ini adalah mengembangkan instrumen penelitian yang sudah ditetapkan sebelumnya. Untuk menganalis digunakan teknik $r$ Product Moment, yang membandingkan perhitungan berdasarkan kriteria kevalidan yaitu suatu item pernyataan disebut valid apabila koefesien rhitung lebih besar dari $r$ tabel pada taraf signifikansi $\alpha=0,05$.

Uji reliabilitas untuk mengetahui tingkat kemantapan. Maksudnya adalah dapat "diandalkan"(dependability ) dan hasilnya "dapat diramalkan" (predictabilit). Suatu instrumen dikatakan reliabel apabila memberikan hasil yang terukur sama terhadap suatu keadaan pada waktu yang berbeda, dengan Alpha Cronbach lebih besar atau sama dengan 0,6 .

\section{Uji Asumsi Klasik}

Metode statistik yang digunakan yaitu analisis linier berganda karena digunakan 3 variabel independen dan 1 variabel dependen. Sebelum dilakukan analisis tersebut, uji asumsi klasik perlu dilakukan terlebih dahulu dengan tujuan hasil regresinya untuk memperkirakan variabel terkait tidak bias.

Uji Normalitas bertujuan untuk menguji variabel dalam penelitian ini model regresinya terdistribusi normal atau mendekati dengan pendekatan grafik Normal $P-P$ of Regresion Standardized Residual. Jika data menyebar disekitar garis diagonal dan mengikuti garis diagonal, maka disimpulkan asumsi normalitas terpenuhi.

Uji autokorelasi menjelaskan tidak saling berpengaruhnya varian residual (e). Untuk mengetahui hasil pengujian ini dilakukan tes Durbin-Watson (Gujarati, 1993:217).

Uji Heteroskedastisitas bertujuan untuk menilai apakah ada ketidaksamaan varian dari residual untuk semua pengamatan pada model regresi linear. Heteroskedastisitas tidak terjadi jika varian residu homogen. Jika probabiltias atau pvalue $>(\alpha=0,05)$ atau nonsignifikan, maka tidak terjadi heteroskedastisitas.

Uji multikolinieritas adalah menguji apakah terdapat hubungan antar variabel bebas (independent) dalam model regresi. Pengujian multikolinieritas dilakukan dengan menghitung nilai VIF (Variance Inflating Factor), apabila lebih kecil dari 5\% maka multikolinieritas tidak terjadi.

\section{HASIL DAN PEMBAHASAN Pengujian Validitas dan Reliabilitas}

Berdasar hasil SPSS diperoleh nilai signifikansi pada masing-masing variabel 0,2973 pada variabel pertama, 0,2973 untuk variabel kedua, dan 0,2973 untuk variabel ketiga. Dapat disimpulkan butir pertanyaan 
pada variabel motivasi, komunikasi dan budaya organisasi telah valid.

Sesuai hasil pengolahan data dengan SPSS semua variabel nilai koefisien Alpha Cronbach nya lebih dari 0,6 sehingga disimpulkan instrumen pertanyaan yang dipakai sudah reliable atau sangat reliable

\section{Pengujian Asumsi Klasik}

Hasil Uji Normalitas pada penelitian ini menunjukkan pola yang yang terbentuk pada histogram mendekati benul bel dan plot linier menunjukkan data yang bergerak mengikuti garis linier diagonal, maka disimpulkan bahwa data berdistribusi normal. Begitu juga dengan Uji Autokorelasi, menunjukkan nilai statistik uji $\mathrm{dw}$ berada diantara nilai dU dan 4 - dU maka pada kasus ini tidak terjadi autokorelasi. Sedangkan metode Uji Heterokedastisitas dalam penelitian ini menggunakan metode grafik dengan memakai grafik plot dan sesuai hasil yang ada terlihat penyebaran titik yang acak tanpa bentuk pola tertentu. Hal ini menunjukkan indikasi tidak terjadi heterokedastisitas. Untuk Uji Multikolinieritas, sesuai hasil pengolahan data diperoleh nilai tolerance lebih besar dari 0.10 , nilai VIF kurang dari 10 maka disimpulkan tidak terjadi asumsi multikolinearitas.

\section{Analisis Regresi Linier Berganda}

Tabel 1. Hasil Analisa Statistik

\begin{tabular}{lccccc}
\hline & \multicolumn{2}{c}{$\begin{array}{c}\text { Unstandardized } \\
\text { Coefficients }\end{array}$} & \multicolumn{3}{c}{$\begin{array}{l}\text { Standardized } \\
\text { Coefficients }\end{array}$} \\
\cline { 2 - 6 } Model & $\mathrm{B}$ & \multicolumn{1}{c}{ Std. } \\
Error & Beta & $\mathrm{t}$ & Sig. \\
\hline 1 (Constant) & 2.164 & 1.912 & & 1.132 & .265 \\
X1 & .351 & .134 & .370 & 2.619 & .013 \\
X2 & .130 & .178 & .109 & .730 & .470 \\
X3 & .224 & .064 & .499 & 3.509 & .001 \\
\hline Sumber : data diolah & & & &
\end{tabular}

Dari analisa statistik pada tabel 1 di atas didapatkan sebuah persamaan:

$$
\mathrm{Y}=2.164+0,370 \mathrm{X} 1+0,109 \mathrm{X} 2+0,499
$$

$\begin{array}{ccc}\text { Hasil } & \text { regresi } & \text { tersebut } \\ \text { menggambarkan } & \text { pengaruh } & \text { variabel }\end{array}$

independent terhadap variabel dependent, dengan nilai konstanta sebesar 2,164 menunjukkan bahwa jika tidak ada motivasi, komunikasi dan budaya organisasi maka tingkat kinerja karyawan di Universitas Merdeka Pasuruan adalah 2.164 satuan score. Koefisien regresi $\mathrm{X} 1$ sebesar 0,370 memberikan gambaran jika variabel motivasi meningkat sebesar 1 satuan maka kinerja karyawan meningkat pula sebesar 0,370 satuan atau berpengaruh positif terhadap kinerja karyawan. Koefisien regresi X2 sebesar 0,109 mengartikan jika variabel komunikasi meningkat sebesar 1 satuan maka kinerja karyawan naik sebesar 0,109 satuan atau berpengaruh positif terhadap kinerja karyawan. Sementara koefisien regresi X3 sebesar 0,499 mengartikan jika variabel budaya organisasi meningkat sebesar 1 satuan maka kinerja naik pula sebesar 0,499 satuan atau berpengaruh positif terhadap kinerja karyawan.

\section{Pembahasan}

Pada pengujian hipotesis, diperoleh nilai signifikansi uji $\mathrm{F}$ sebesar 0.000. Karena nilainya dibawah 5\% maka $\mathrm{H}_{0}$ ditolak. Artinya, dengan tingkat kepercayaan sebesar 95\% dapat dikatakan variabel motivasi, komunikasi dan budaya organisasi mempunyai pengaruh secara bersama-sama terhadap kinerja karyawan.

Berdasar hasil analisa statistik pada tabel 1, variabel motivasi mempunyai nilai signifikan 0,013 lebih kecil dari taraf keyakinan 0,05 maka $\mathrm{H} 0$ ditolak. Sehingga dapat disimpulkan ada pengaruh positif dan signifikan motivasi terhadap kinerja karyawan yaitu sebesar $0.370(=37 \%)$. Hasil penelitian ini sesuai dengan hasil penelitian (Hastuti, Sularso, 2013), (Rahmayanti, 2014), (Prihono,Budhiarta, 2016), (Amalia \& Fakhri, 2016) yang menyatakan bahwa secara signifikan motivasi mempengaruhi kinerja seorang karyawan.

Untuk variabel komunikasi mempunyai nilai signifikan 0.470 lebih besar dari taraf keyakinan 0,05 maka Ho diterima. Hal ini menunjukkan bahwa komunikasi tidak mempunyai pengaruh signifikan 
terhadap kinerja, Hasil pnelitian ini tidak sejalan dengan hasil penelitian yang dilakukan oleh (Hastuti, Sularso, 2013),(Lakoy, 2015), (Srimiatun \& Prihatinta, 2017) serta (Samodro \& Lestari, 2018) dimana dalam penelitian tersebut diperoleh pembuktian empiris bahwa komunikasi berpengaruh dengan kinerja karyawan.

Sedangkan untuk variabel budaya organisasi nilai signifikannya 0.001 lebih kecil dari taraf keyakinan 0,05 maka $\mathrm{H} 0$ ditolak. Sehingga dapat dinyatakan ada pengaruh positif budaya organisasi terhadap kinerja karyawan sebesar $0.499 \quad(=49.9 \%)$. Hasil penelitian ini sejalan dengan penelitian (Soedjono, 2005), (Taurisa Chaterina, 2012), (Arianty Nel, 2014), (Baan, 2015), (Prihono,Budhiarta, 2016) serta (Sagita, Susilo, \& Cahyo W.S, 2018) yang menyimpulkan terdapat pengaruh positif antara budaya organisasi terhadap kinerja.

Berdasarkan nilai koefisien regresi, dari ketiga variabel bebas yang diteliti, faktor budaya organisasi yang berpengaruh dominan dibandingkan dengan faktor motivasi dan komunikasi.

\section{Kesimpulan}

Motivasi dan budaya organisasi berpengaruh siginifikan terhadap kinerja, sedangkan komunikasi tidak mempunyai pengaruh signifikan terhadap kinerja karyawan tenaga kependidikan di Universitas Merdeka Pasuruan. Dari ketiga variabel bebas yang diteliti, faktor budaya organisasi yang berpengaruh dominan dibandingkan dengan faktor motivasi dan komunikasi.

\section{DAFTAR PUSTAKA}

Amalia, S., \& Fakhri, M. (2016). Pengaruh Motivasi terhadap Kinerja PT. Gramedia Asri Cabang Emerald Bintaro. Computech Dan Bisnis, 10, 119-127.

AP Mangkunegara, A. P. (2009). Manajemen Sumber Daya Manusia Perusahaan. Bandung: Rosda.

Ardana, I. K., Mujiati, N. W., \& Utama, I. W. M. (2012). Manajemen Sumber
Daya Manusia (1st ed.). Yogyakarta: Graha Ilmu.

Arianty Nel. (2014). Pengaruh Budaya Organisasi terhadap Kinerja pegawai. Manajemen Dan Bisnis, 14. Retrieved from ISSN 1693-7619

Baan, Y. F. (2015). Pengaruh Budaya Organisasi terhadap kinerja Karyawan Hotel Grand Victoria. EJournal Ilmu Administrasi Bisnis, 3(3), 675-686. Retrieved from journal.adbisnis.fisip-unmul.ac.id

Dharma, S. (2012). Manajemen Kinerja Falsafah Teori dan Penerapannya. Yogyakarta: Pustaka Pelajar.

Fred, L. (1995). Perilaku Organisasi. Yogyakarta: Andi.

Gibson, $\quad$ J. L.

Organisasi:perilaku,struktur,proses

(N. Andriani, ed.). jakarta: Binarupa Aksara.

Hasibuan, M. S. (2016). Manajemen Sumber Daya Manusia (revisi). Jakarta: PT. Bumi Aksara.

Hastuti, Sularso, K. (2013). Pengaruh Komunikasi, Motivasi dan Etos Kerja terhadap Kinerja Pegawai Koordinator Unit Pelaksana Teknis Dinas Pendapatan Propinsi Jawa Timur di Probolinggo. JEAM, XII. Retrieved from issn:1412-5366

Lakoy, A. C. (2015). Pengaruh Komunikasi, Kerjasama Kelompok, dan Kreativitas terhadap Kinerja karyawan pada Hotel Aryaduta Manado. EMBA, 3, 981-991. Retrieved from issn:230211

Moenir, H. A. . (2016). Manajemen Pelayanan Umum di Indonesia (12th ed.). Bumi Aksara.

Newstrom, J. W., \& Davis, K. E. (2002). Human Behavior at Work (11th ed.). McGraw-Hill.

Prihono,Budhiarta, A. (2016). Pengaruh Motivasi, Budaya Organisasi dan Spiritualitas pada Kinerja Pegawai Kantor Pelayanan Perbendaharaan Negara di Propinsi Bali. Ekonomi Dan Bisnis Universitas Udayana, 2063-2090. Retrieved from 
issn:2337-3067

Purwanto, A. J. (2011). Metode Penelitian Kuantitatif dan Administrasi Publik dan Masalah Sosial. Yogyakarta: Gava Media.

Rahmayanti. (2014). Pengaruh Motivasi Kerja terhadap Kinerja Karyawan pada CV. Puyra Kaltim Samarinda. Ilmu Administrasi Bisnis, 2, 215-229. Retrieved from ejournal.adbisnis.fisip-unmul.ac.id

Rakhmat, J. (2008). Psikologi Komunikasi (26th ed.). Remaja Rosdakarya.

Rivai Veitzal. (2013). Manajemen SDM untuk Perusahaan. Bandung: Rajawali Pers.

Robbins, S., \& Judge. (2008). Perilaku Organisasi. Jakarta: Salemba Empat.

Sagita, A. A., Susilo, H., \& Cahyo W.S, M. (2018). Pengaruh Budaya Organisasi terhadap Kinerja dengan Motivasi sebagai Variabel Moderator. Administrasi Bisnis, 57(1).

Samodro, C. A., \& Lestari, S. P. (2018). Pengaruh Komunikasi Organisasi Atasan Bawahan terhadap Kinerja Karyawan Koperasi BMT Fosilatama. Egaliter, 1(2).

Soedjono. (2005). Pengaruh Budaya Organisasi terhadap Kinerja Organisasi dan Kepuasan Kerja Karyawan pada Terminal Penumpang Umum di Surabaya. Manajemen Dan Kewirausahaan, 7, 22-47. Retrieved from

http://puslit.petra.ac.id/ puslit/journal s/

Srimiatun, \& Prihatinta, T. (2017). Pengaruh Komunikasi dan Konflik terhadap Kinerja Tenaga Kependidikan Politeknik Negeri Madiun. Epicheirisi, 1(1).

Taurisa Chaterina, R. (2012). Analisis Pengaruh Budaya Organisasi dan Kepuasan Kerja terhadap Komitmen Organisasional dalam Meningkatkan Kinerja Karyawan. Bisnis Dan Ekonomi (JBE), 19, 170-187. Retrieved from issn:1412-3126

Terry, G. R., \& Rue, L. W. (2019). Dasar-
Dasar Manajemen (B. S. Fatmawati, ed.). Jakarta: Bumi Aksara.

Uno, H. B. (2007). Teori Motivasi dan Pengukurannya. Jakarta: Bumi Aksara. 